\title{
Perangkat Lunak Pengajuan Dana Bos Pada Kementerian Agama (Kemenag) Ogan Komering Ilir (OKI) Berbasis Web
}

\author{
Sakban Arifin¹, Jemakmun², Hutrianto ${ }^{3}$ \\ 12,3Informatics Departement, Universitas Bina Darma, Palembang, Indonesia \\ Email: sakbanarifin93@gmail.com , jemakmun_ckp@yahoo.com², hutrianto@binadarma.ac.id³
}

\begin{abstract}
The software for submitting School Operational Assistance funds is an improvement in the quality of education by providing educational funding from School Operational Assistance National Budget funds. Ministry of Religion and schools still experience difficulties in carrying out bookkeeping usage and the results of spending from School Operational Assistance funds. So that this study aims to create a web-based application that makes it easy for admins to examine all School Operational Assistance funds and input submissions \& reports that have collected report data. Submission is an activity aimed at providing information about the causes and consequences of a policy that is being implemented, while School Operational Assistance is a government program which is basically to provide funding for non-personnel operational costs. In this study data collection was carried out by observation, interview, and literature methods and the development of software prototyping systems as the basis of the concept of working models with the aim of developing the model into a final system.
\end{abstract}

Keywords: Software, School Operational Assistance, funds from the State Budget

\section{PENDAHULUAN}

Salah satu bentuk nyata pemerintah dalam upaya peningkatan kualitas pendidikan adalah dengan memberikan pendanaan pendidikan yang signifikan dari sumber dana Anggaran Pendapatan dan Belanja Negara (APBN) adalah Bantuan Operasional Sekolah (BOS). Program BOS merupakan program nasional di bidang pendidikan yang menyerap anggaran besar dan langsung berhubungan dengan hajat hidup masyarakat luas. Bantuan Operasional Sekolah (BOS) diberikan oleh pemerintah pada lembaga pendidikan tingkat 12 tahun, yaitu MI, MTs dan MA, sebagai pengganti dana operasional yang biasa dipungut dari anak-anak didik lembaga pendidikan tersebut, sehingga dengan adanya dana Bantuan Operasional Sekolah ini semua peserta didik setiap lembaga yang mendapatkan bantuan BOS ini dibebaskan dari iuran SPP yang biasanya dibayar setiap bulan. Program BOS bertujuan untuk meringankan 
beban masyarakat terhadap pembiayaan pendidikan dalam rangka Wajib Belajar Sembilan Tahun.

Madrasah Ibtida'iyah (MI), Madrasah Tsanawiyah (MTs), dan Madrasah Aliyah (MA) merupakan sekolah yang menerima dana Bantuan Opersional Sekolah (BOS) khususnya di daerah kabupaten Ogan Komering llir (OKI) sumateraselatan. BOS diberikan dan dikelola oleh sekolah dengan diawasi oleh berbagai pihak, baik instansi resmi maupun masyarakat (komite sekolah). Dalam pelaksana program BOS, pihak sekolah masih mengalami kesulitan dalam melakukan pembukuan penggunaan dana BOS, serta kerepotan memenuhi tuntutan bentuk standar format laporan dana BOS. Saat ini, pihak sekolah masih melakukan pemrosesan pengolahan/pencatatan laporan keuangan BOS secara manual, Sehingga terjadi human error seperti kesalahan dalam penginputan data yang menyebabkan data menjadi tidak akurat dan relevan, sangatlah mungkin terjadi, serta tidak adanya transparasi dalam pelaporan dan penggunaan dana BOS selama ini. Menanggapi adanya permasalahan tersebut, maka perlu adanya sistem informasi berbasis komputer. (Amborowati \& Marco, 2016).

\section{METHODS}

\subsection{Metode Pengumpulan Data}

Metode yang digunakan untuk pengumpulan data dalam penelitian ini adalah sebagai berikut:

1) Wawancara (Interview)

Merupakan suatu pengumpulan data yang dilakukan dengan cara tanya jawab atau dialog dengan pihak pihak yang terkait dengan penelitian yang dilakukan.

2) Studi pustaka

Mengumpulkan data dengan cara mencari dan mempelajari data dari dari buku buku, jurnal jurnal ilmiah dari internet ataupun referensi lain yang berhubungan dengan laporan penelitian skripsi ini, serta buku buku yang digunakan penulis sebagai referensi. Adapun metode yang digunakan penulis dalam perancangan dapat dilihat pada daftar pustaka.

3) Survey

Merupakan proses verifikasi yang dilakukan dengan cara survey langsung ke lapangan, dalam hal ini survey dilakukan di Univesitas Bina Darma yang digunakan sebagai tempat beroperasinya sistem. 


\subsection{Metode Pengembangan Sistem}

Prototyping perangkat lunak (software prototyping) adalah salah satu metode siklus hidup sistem yang didasarkan pada konsep model bekerja (working model). Tujuannya adalah mengembangkan model menjadi sistem final. Secara ideal prototype berfungsi sebagai subuah mekanisme untuk mengidentivikasi kebutuhan software, bila prototype yang sedang bekerja dibangun pengembangannya harus menggunakan fragmenfragmen program yang ada atau mengaplikasikan alat-alat bantu (contohnya : report generator, windows manager dIl) dimana memungkinkan program yang bekerja untuk dimunculkan secara cepat. Ciri khas dari metodologi ini adalah pengembang sistem (system developer), klien, dan pengguna dapat melihat dan melakukan eksperimen dengan bagian dari sistem komputer dari sejak awal proses pengembangan. Prototyping adalah suatu proses yang memungkinkan developer membuat sebuah model software, metode ini baik digunakan apabila client tidak bisa memberikan informasi yang maksimal mengenai kebutuhan yang diinginkannya. Dalam hal seperti ini, pendekatan prototyping untuk software engineering merupakan langkah yang terbaik. Sebuah desain cepat berfokus pada representasi dari aspek-aspek perangkat lunak yang akan dilihat oleh semua pengguna (misalnya, tata letak antarmuka manusia atau tampilan output format). (Pressman, 2012).

Prototyping perangkat lunak (software prototyping) atau siklus hidup menggunakan protoyping (life cycle using prototyping) adalah salah satu metode siklus hidup sistem yang didasarkan pada konsep model bekerja (working model). Tujuannya adalah mengembangkan model menjadi web browsing teknologi sistem reservasi yang akan dibuat final. Artinya sistem akan dikembangkan lebih cepat dari pada metode tradisional dan biayanya menjadi lebih rendah. Ada banyak cara untuk memprotoyping, begitu pula dengan penggunaannya. Ciri khas dari metodologi ini adalah pengembang sistem (system developer), klien, dan pengguna dapat melihat dan melakukan eksperimen dengan bagian dari sistem komputer dari sejak awal proses pengembangan.

Prototype membantu dalam menemukan kebutuhan di tahap awal pengembangan,terutama jika klien tidak yakin dimana masalah berasal. Prototype bertujuan agar pengguna dapat memahami alur proses system 
dengan tampilan dan simulasi yang terlihat siap digunakan. Model Prototype terdiri dari 5 tahapan yaitu sebagai berikut:

1) Komunikasi, tahapan ini mengidentifikasi permasalahanpermasalahan yang ada, serta informasi-informasi lain yang diperlukan untuk pengembangan system. Perencanaan, tahapan ini dikerjakan dengan kegiatan penentuan sumberdaya,spesifikasi untuk pengembangan berdasarkan kebutuhan system, dan tujuanberdasarkan pada hasil komunikasi yang dilakukan agar pengembangan dapat sesuai dengan yang diharapkan. Komunikasi yang dilakukan adalah dengan cara mewawancarai kasi penmad, bagian pengolahan data BOS;

2) Perencanaan, tahapan ini dikerjakan dengan kegiatan penentuan sumberdaya, spesifikasi untuk pengembangan berdasarkan kebutuhan system, dan tujuan berdasarkan pada hasil komunikasi yang dilakukan agar pengembangan dapat sesuai dengan yang diharapkan;

3) Pemodelan, tahapan selanjutnya ialah representasi atau menggambarkan model system yang akan dikembangkan seperti proses dengan perancangan menggunakan Use Case Diagram, Activity Diagram, Class Diagram relasi antara entitas yang diperlukan dan perancangan antarmuka dari system yang akan dikembangkan;

4) Kontruksi, tahapan ini digunakan untuk membangun, menguji coba system yang dikembangkan. Proses instalasi dan penyediaan user-support juga dilakukan agar system dapat berjalan dengan sesuai;

5) Penyerahan, tahapan ini dibutuhkan untuk mendapatkan feedback dari pengguna, sebagai hasil evaluasi dari tahapan sebelumnya dan implementasi dari system yang dikembangkan.

\subsection{Kebutuhan Data}

Kebutuhan data menggambarkan data apa saja yang digunakan pada system perangkat lunak monitoring dana BOS. Data yang digunakan pada perangkat lunak monitoring dana BOS terdiri dari beberapa:

Tabel 1 Kebutuhan Data

\begin{tabular}{ccc}
\hline No & Nama Data & Fungsi \\
\hline 1. & Format Pengajuan RKAM dana & Menginformasikan data dari pada sekolah
\end{tabular}


https://journal-computing.org/index.php/journal-ita/index

\begin{tabular}{|c|c|c|}
\hline No & Nama Data & Fungsi \\
\hline & BOS & yang mengajukan pengajuan RKAM dan \\
\hline 2. & Penggunaan Dana Form K1 & pelaporan Dana BOS pada Kementrian \\
\hline 3. & $\begin{array}{l}\text { Rencana Kegiatan \& Anggaran } \\
\text { Madrasah Form K2 }\end{array}$ & $\begin{array}{l}\text { Agama Ogan Komering llir, sehingga } \\
\text { pengajuan dan pelaporan akan dimonitor }\end{array}$ \\
\hline 4. & Buku Pembantu KAS Form K3 & oleh pihak Kemenag OKI dan di Acc \\
\hline 5. & Buku Pembantu KAS Form K4 & Pengajuan RKAM dan pelaporan dan BOS \\
\hline 6. & Buku Pembantu Bank Form K5 & tersebut.. \\
\hline 7. & Buku Pembantu Pajak Form K6 & \\
\hline
\end{tabular}

\section{HASIL DAN PEMBAHASAN}

\subsection{Hasil}

Hasil dari penelitian ini adalah sebuah database dengan nama dana_bos dan sebuah perangkat lunak monitoring dana bos pada kemenag OKI. Adapun perangkat lunak yang dibuat adalah berbasis website menggunakan bahasa pemograman PHP dan MySQL sebagai dataabasenya. Berikut adalah tampilan dari struktur database dari perangkat lunak yang telah dibuat.

1) Halaman Login

Pada tampilan tersebut dapat dilihat tampilan login dengan username dan password tampilan menu login pada admin sekolah dan admin kemenag memiliki tampilan yang sama namun masing-masing user memiliki menu yang berbeda didalam sistem web.

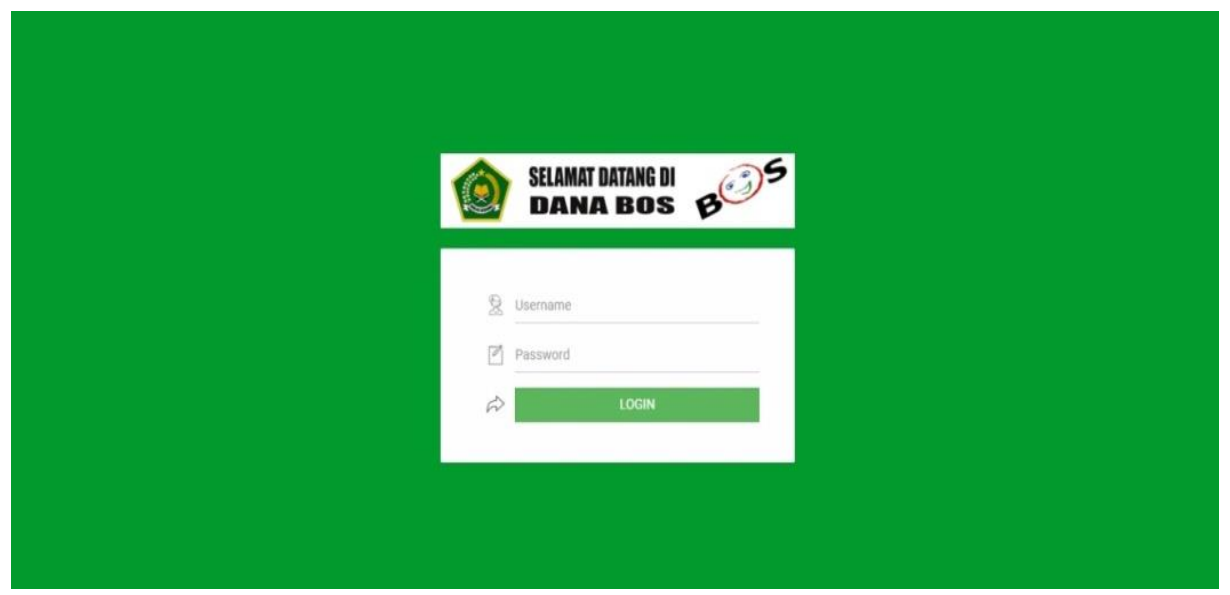

Gambar 1. Tampilan Halaman Login 
2) Halaman Awal Admin Sekolah \& Kemenag

Halaman utama perangkat lunak ini dapat diakses apabila sebelumnya admin sekolah \& admin kemenag melakukan login terlebih dahulu, pada halaman ini terdapat beberapa menu diantaranya menu RKAM (Pengajuan), Daftar RKAM (Laporan RKAM dana BOS), pada admin kemenag terdapat hasil pengajuan \& laporan dana bos RKAM dari madrasah, dan admin kemenag yang akan menyetujui (Acc) pengajuan RKAM \& laporan RKAM dana BOS.

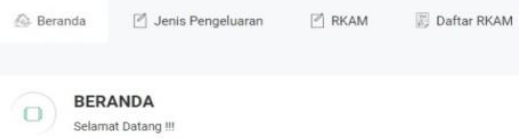

Gambar 2. Halaman Awal Admin Sekolah

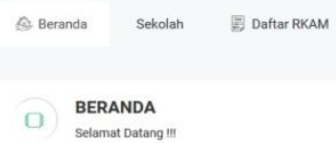

Gambar 3. Halaman Awal Admin Kemenag

3) Halaman Pengajuan RKAM

Halaman Input pengajuan RKAM merupakan halaman yang digunakan untuk melakukan pengajuan RKAM yang menjadi format RKAM (Recana 
Kegiatan dan Anggaran Madrasah), dalam proses penginputan pengajuan RKAM. Agar admin sekolah dapat melakukan Input pengajuan RKAM, terlebih dahulu admin sekolah harus melakuan login. Pada menu ini admin sekolah dapat menambahkan data pengajauan RKAM, ajukan ataupun menghapus data pengajuan RKAM dan mencetak data yang telah diinput.

\section{(c) DaMaboskavenG}

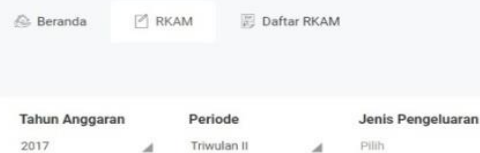

RENCANA KEGIATAN DAN ANGGARAN MADRASAH (RKAM)

\begin{tabular}{|c|c|c|c|c|c|c|c|}
\hline \multirow{2}{*}{ \#\# } & \multirow{2}{*}{ No.Kode } & \multirow{2}{*}{$\begin{array}{c}\text { Pengeluaran } \\
\text { Uraian }\end{array}$} & \multirow{2}{*}{ Jumlah } & \multicolumn{4}{|c|}{ Triwulan } \\
\hline & & & & 1 & "I & & IV \\
\hline \multirow[t]{4}{*}{1} & 2 & 3 & 4 & 5 & 6 & 7 & 8 \\
\hline & 1 & PENGEMBANGAN PERPUSTAKAAN & & & & & \\
\hline & & & & & & & \\
\hline & " & KEGIATAN PENERIMAAN SISWA BARU & & & & & \\
\hline
\end{tabular}

Gambar 4. Halaman Pengajuan RKAM

4. Halaman Tambah Jenis Pengeluaran

Halaman jenis pengeluaran merupakan halaman yang digunakan untuk menambahkan jenis pengeluaran pada admin sekolah yang menjadi format RKAM, terlebih dahulu admin sekolah harus melakuan login. Pada menu ini admin sekolah dapat menambahkan jenis pengeluaran RKAM, mengedit ataupun menghapus data.
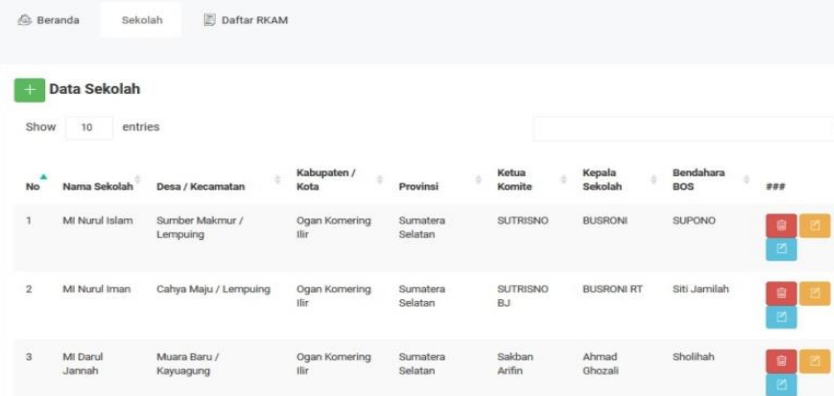

Gambar 5. Halaman Tambah Jenis Pengeluaran 


\section{Halaman Upload Berkas Pengajuan}

Halaman upload berkas pengajuan ini merupakan halaman yang digunakan untuk melakukan upload berkas pengajuan yang menjadi format persyaratan dari Kemenag dalam proses penguploadan berkas pengajuan. Agar admin sekolah dapat melakukan upload berkas pengajuan, terlebih dahulu admin sekolah harus melakuan login. Pada menu ini admin sekolah dapat menambahkan file berkas pengajuan, hapus, edit, serta ajukan berkas pengajuan, upload berkas sesuaikan dengan berkas yang telah diberitahukan oleh admin kemena. Dan akan disetujui oleh admin kemenag jika admin sekolah telah mengajukan berkas pengajuan.

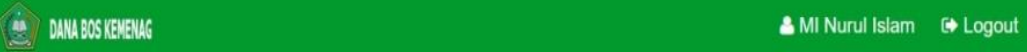

Berkas RENCANA KEGIATAN DAN ANGGARAN MADRASAH (RKAM) A Ainthen Bathe RKAM

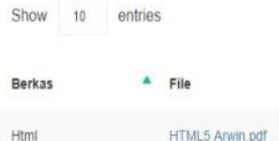

\section{Halaman Laporan RKAM Dana BOS}

Halaman input laporan RKAM dana BOS merupakan halaman yang digunakan untuk melakukan laporan RKAM dana BOS yang menjadi format BOS-K3, K4, K5 dalam proses penginputan laporan RKAM dana BOS. Agar admin sekolah dapat melakukan input laporan RKAM dana BOS ini, terlebih dahulu admin sekolah harus melakuan login. Pada menu ini admin sekolah dapat menambahkan data form BOS-K3, K4, K5, menghapus, jika selesai penginputan dilanjutkan menekan ajukan laporan RKAM dana BOS ke admin kemenag. 


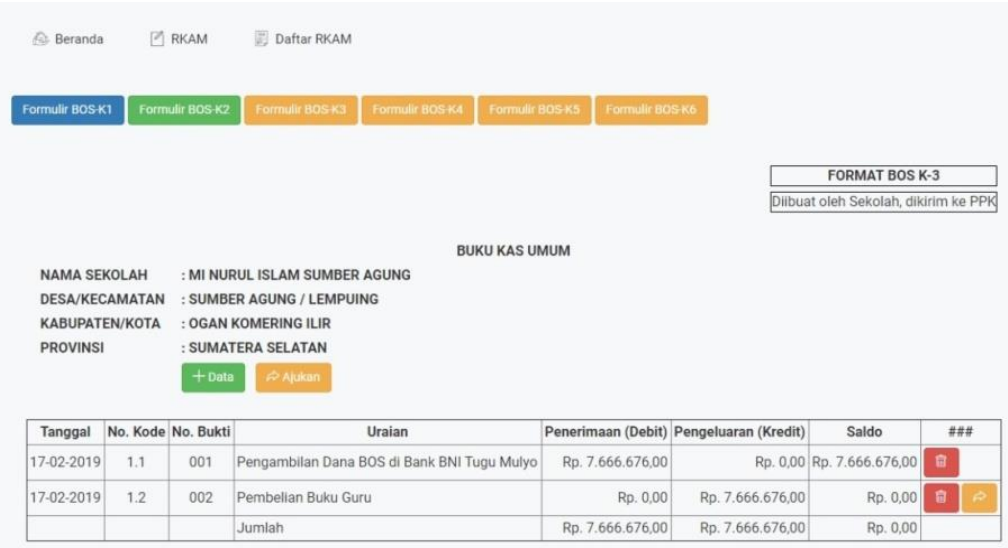

Gambar 7. Halaman Laporan RKAM Dana BOS

\section{Halaman Acc Pengajuan RKAM \& Laporan Dana BOS}

Halaman Acc pengajuan RKAM \& laporan dana BOS merupakan halaman yang digunakan untuk menyetujui (Acc) yang telah mengajukan pengajuan RKAM \& laporan RKAM oleh admin sekolah. Agar admin kemenag dapat melakukan pengecekan dan menyetujui (Acc) pengajuan RKAM \& laporan RKAM ini, terlebih dahulu admin kemenag harus melakuan login. Pada menu ini admin kemenag dapat menyetujui (Acc) pengajuan RKAM \& laporan RKAM dibagian data pengajuan RKAM yaiitu status pengajuan, status berkas pengajuan, status pelaporan, dan sehingga admin kemenag dapat monitor atau melihat satu persatu dengan yang telah diajukan oleh admin sekolah.

Q Beranda Sekolah Daftar RKAM

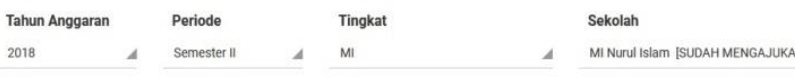

Data Pengajuan RKAM

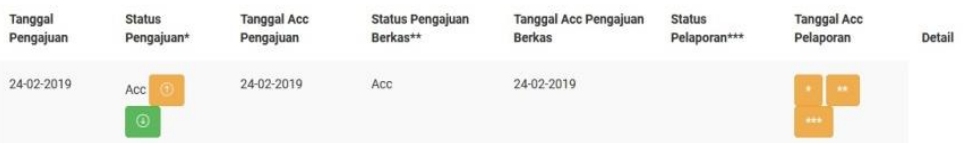

Gambar 8. Halaman Acc Pengajuan RKAM \& Laporan Dana BOS 


\section{Halaman Tambah Data Sekolah \& User}

Halaman tambah data sekolah \& user merupakan halaman yang digunakan untuk menambah data sekolah baru dan user halaman ini pada halaman ini admin sekolah dapat meyimpan, menghapus, menedit dan menambahkan user, terlebih dahulu admin sekolah harus melakukan login.

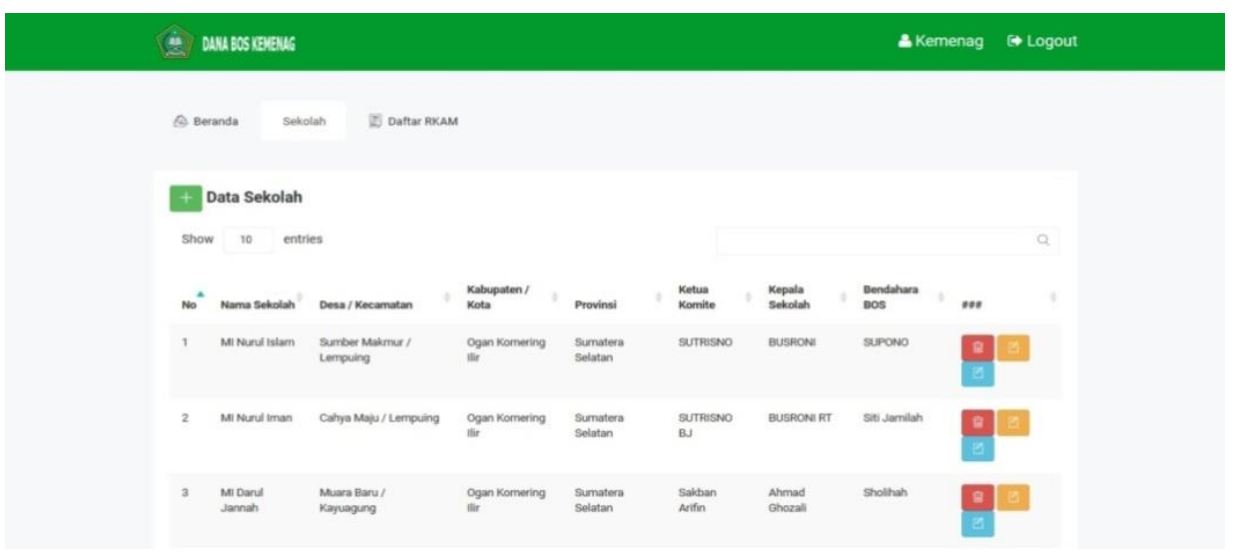

Gambar 9. Halaman Tambah Data Sekolah \& User

\subsection{PEMBAHASAN}

Setelah proses pembuatan sistem telah selesai dibuat maka Penulis melakukan pengujian sistem. Pengujian ini menggunakan black box testing yaitu pengujian berdasarkan sudut pandang pengguna. Penulis mengevaluasi hanya dari tampilan dan fungsi-fungsinya, tanpa mengetahui apa sesungguhnya yang terjadi dalam proses detailnya atau hanya mengetahui hasil keluarannya saja.

\section{KESIMPULAN}

Berdasarkan hasil penelitian yang telah dilakukan dan hasil pembahasan yang telah diuraikan pada bab-bab sebelumnya, maka dapat ditarik kesimpulan bahwa:

1. Perangkat lunak yang dibuat bagi Kementerian Agama OKI dalam melakukan pemantauan pengajuan RKAM dan pelaporan pada kemenag, begitu juga madrasah dapat menginput rincian pengajuan RKAM dan laporan dana BOS dari hasil kegiatan;

2. Perangkat lunak yang dibuat dapat memudahkan Kemenag OKI dalam melakukan pengawasan laporan dana BOS oleh madrasah. 


\section{DAFTAR PUSTAKA}

A.S, R., \& Shalahuddin, M. (2014). Rekayasa Perangkat Lunak. Bandung: Informatika.

Amborowati, A., \& Marco, R. (2016). Analisis Pengelolaan Dan Monitoring Dana Bantuan Sekolah (BOS) Menggunakan Sistem Informasi Berbasis Website Pada SLTP Di Daerah Istimewa Yogyakarta. Jurnal I/miah DASI, 6-14.

Amborowati, A., \& Marco, R. (2016). Perancangan Sistem Pengelolaan Dan Monitoring Bantuan Operasional Sekolah (BOS) Pada SLTP Yogyakarta Dalam Upaya Pengendalian Dana. Jurnal Telematika, 11-36.

Betha, S. I. (2012). Pemograman Web PHP. Bandung: Informatika.

Hidayatullah, P., \& Kawisatra, J. K. (2017). Pemograman Web. Bandung: Informatika.

Kawandi. (2015). Evaluasi Pengelolaan Dana Bantuan Operasional Sekolah Di SD Negeri 027 Tarakan. Jurnal Kebijakan dan Pengembangan Pendidikan , 66-74.

Maudi, M. F., Nugraha, A. L., \& Sasmito, B. (2014). Desain Aplikasi Sistem Informasi Pelanggan PDAM Berbasis Web GIS (Studi Kasus: Kota Demak). Jurnal Geodesi Undip , 98-110.

Pressman, R. S. (2012). Rekayasa Perangkat Lunak. Yogyakarta: Andi. Edisi ketujuh.

Pressman, R. S. (2010). Software Engineering : A Pratitioner's Approach. New York: McGraw-Hill.

Rohi, A. (2015). Web Programming is Easy. Bandung: Elex media komputindo. 